\title{
Eurolntervention
}

\section{A comparison of patient characteristics and 30-day mortality outcomes after transcatheter aortic valve implantation and surgical aortic valve replacement for the treatment of aortic stenosis: a two-centre study}

\begin{abstract}
Nicolo Piazza1, MD, FRCPC; Menno van Gameren², MD; Peter Jüni3,4, MD, PhD; Peter Wenaweser ${ }^{5}$, MD; $^{3}$ Thierry Carrel $^{6}$, MD; Yoshinobu Onuma ${ }^{1}, \mathrm{MD}_{\text {; }}$ Brigitta Gahl ${ }^{6}$, Dipl.-Math; Gerrit Hellige ${ }^{5}$, MD; Amber Otten ${ }^{1}$, MD; Arie-Pieter Kappetein², MD, PhD; Johanna J.M. Takkenberg ${ }^{2,7}$, MD, PhD; Ron van Domburg7, PhD; Peter de Jaegere', MD, PhD; Patrick W. Serruys ${ }^{1 *}$, MD, PhD; Stephan Windecker ${ }^{4,5}$, MD, PhD

1. Department of Interventional Cardiology, Thoraxcenter, Erasmus Medical Center, Rotterdam, The Netherlands; 2. Department of Cardiac Surgery, Thoraxcenter, Erasmus Medical Center, Rotterdam, The Netherlands; 3. Division of Clinical Epidemiology and Biostatistics, Institute of Social and Preventive Medicine, University of Bern, Bern, Switzerland; 4. CTU Bern, Bern University Hospital, Bern, Switzerland; 5. Department of Cardiology, Bern University Hospital, Bern, Switzerland; 6. Department of Cardiac Surgery, University of Bern Hospital, Bern, Switzerland; 7. Department of Biostatistics and Epidemiology, Erasmus Medical Center, Rotterdam, The Netherlands
\end{abstract}

The authors have no conflict of interest to declare.

\section{KEYWORDS}

Aortic stenosis, surgical aortic valve replacement, transcatheter aortic valve implantation, risk-adjustment

\begin{abstract}
Aims: It is unclear whether transcatheter aortic valve implantation (TAVI) addresses an unmet clinical need for those currently rejected for surgical aortic valve replacement (SAVR) and whether there is a subgroup of high-risk patients benefiting more from TAVI compared to SAVR. In this two-centre, prospective cohort study, we compared baseline characteristics and 30-day mortality between TAVI and SAVR in consecutive patients undergoing invasive treatment for aortic stenosis.

Methods and results: We pre-specified different adjustment methods to examine the effect of TAVI as compared with SAVR on overall 30-day mortality: crude univariable logistic regression analysis, multivariable analysis adjusted for baseline characteristics, analysis adjusted for propensity scores, propensity score matched analysis, and weighted analysis using the inverse probability of treatment (IPT) as weights. A total of 1,122 patients were included in the study: 114 undergoing TAVI and 1,008 patients undergoing SAVR. The crude mortality rate was greater in the TAVI group (9.6\% vs. 2.3\%) yielding an odds ratio [OR] of 4.57 (95\%-CI 2.17-9.65). Compared to patients undergoing SAVR, patients with TAVI were older, more likely to be in NYHA class III and IV, and had a considerably higher logistic EuroSCORE and more comorbid conditions. Adjusted OR depended on the method used to control for confounding and ranged from 0.60 (0.11-3.36) to 7.57 (0.91-63.0). We examined the distribution of propensity scores and found scores to overlap sufficiently only in a narrow range. In patients with sufficient overlap of propensity scores, adjusted OR ranged from 0.35 (0.04-2.72) to 3.17 (0.31 to 31.9). In patients with insufficient overlap, we consistently found increased odds of death associated with TAVI compared with SAVR irrespective of the method used to control confounding, with adjusted OR ranging from 5.88 (0.67-51.8) to 25.7 (0.88-750). Approximately one third of patients undergoing TAVI were found to be potentially eligible for a randomised comparison of TAVI versus SAVR. Conclusions: Both measured and unmeasured confounding limit the conclusions that can be drawn from observational comparisons of TAVI versus SAVR. Our study indicates that TAVI could be associated with either substantial benefits or harms. Randomised comparisons of TAVI versuS SAVR are warranted.
\end{abstract}

\footnotetext{
* Corresponding author: Department of Cardiology, Erasmus Medical Center, Thoraxcenter, Ba 583, Erasmus MC, 's-Gravendijkwal 230,3015 CE Rotterdam, The Netherlands 


\section{Introduction}

Transcatheter aortic valve implantation (TAVI) is currently restricted to patients with aortic stenosis in whom surgical aortic valve replacement (SAVR) would be associated with a high or prohibitive risk of morbidity and/or mortality. The aim of TAVI is to provide a minimally invasive treatment that is at least as effective and associated with less morbidity and mortality compared to conventional valve surgery in high-risk patients. It is unclear whether TAVI addresses an unmet clinical need for those currently rejected for SAVR and whether there is a subgroup of high-risk SAVR patients who can benefit more from TAVI than SAVR.

Contemporary studies indicate that the 30-day mortality rate following TAVI is $8 \%$ to $12 \%{ }^{1-3}$. Following SAVR, the 30 -day mortality rate in high-risk patient subsets was reported to be between $4.6 \%$ to $13.5 \%$ for octogenarians ${ }^{4-11}$ and $6 \%$ to $33 \%$ for patients with left ventricular dysfunction ${ }^{12,13}$. To our knowledge, direct comparisons between TAVI and SAVR are not yet available. In this two-centre, prospective cohort study, we set out to compare the characteristics at baseline and 30-day mortality rates between TAVI and SAVR in consecutive patients undergoing invasive treatment for aortic stenosis.

\section{Patients and methods}

Between January 1st, 2006 and December 31'st, 2008, we prospectively enrolled consecutive patients with aortic stenosis who underwent invasive treatment for aortic stenosis at the Erasmus Medical Center, Rotterdam, The Netherlands and Bern University Hospital, Bern, Switzerland. The study complies with the Declaration of Helsinki and was approved by the local Research Ethics Committees. All patients provided written informed consent.

\section{Patients and interventions}

Patients were included if they underwent TAVI or SAVR for the treatment of aortic stenosis at one of the two institutions. Patients undergoing invasive treatment who had a primary diagnosis of aortic regurgitation, multiple valve interventions, or concomitant aortic root reconstruction were excluded. Contraindications for TAVI or SAVR typically included sepsis, bleeding diathesis or coagulopathy, any condition considered a contraindication to extracorporeal assistance, or estimated life expectancy of less than one year.

TAVI was performed using the third generation CoreValve ReValving System (Medtronic, Minneapolis, MN, USA). For patients to undergo TAVI, an interventional cardiologist and cardiac surgeon had to agree that conventional open-heart surgery would be associated with excessive morbidity and mortality. Details of the device, and technical aspects of the procedure have been previously published ${ }^{14}$. The procedure was performed with the patient under general anaesthesia or with local anaesthesia and mild sedation depending on patient characteristics. Vascular access was obtained percutaneously using a "pre-closing" device (10 Fr Prostar $\mathrm{XL}$ ) or by surgical cut-down ${ }^{14}$. Coronary revascularisation was performed if deemed necessary prior to or during the index procedure using percutaneous coronary intervention $(\mathrm{PCl})^{15}$.

The choice of implant used and the technique for SAVR was left to the discretion of the treating cardiac surgeon. The procedure was performed with the patient under general anaesthesia using cardiopulmonary bypass. Coronary revascularisation was performed if deemed necessary during the index procedure using coronary artery bypass graft surgery (CABG).

\section{Baseline characteristics}

The selection of baseline characteristics was based on expert opinion and a review of the literature. We considered patient age (years), sex, logistic EuroSCORE ${ }^{16}$, New York Heart Association class, ejection fraction ( $>50 \%, 30-50 \%$, or $<30 \%$ ), creatinine concentration (umol/L), a history of coronary artery disease, myocardial infarction in the previous 90 days, CABG, atrial fibrillation, peripheral vascular disease, cerebrovascular disease, pulmonary hypertension, and COPD.

\section{Procedural characteristics}

We recorded whether the procedure was an emergency measure, defined as a procedure carried out on referral before the beginning of the next working day ${ }^{16}$ and whether there was a concomitant coronary revascularisation using $\mathrm{PCl}$ in patients undergoing TAVI and $C A B G$ in patients undergoing SAVR.

\section{Primary outcome and definitions}

The primary outcome was all-cause mortality within 30 days ${ }^{17}$. Patients were actively followed-up until 30 days after the index procedure and their vital status was confirmed by outpatient clinical visit, telephone visit, review of medical records or through civil registries.

\section{Statistical methods}

We compared baseline characteristics between patients who had undergone TAVI and SAVR using a $\chi^{2}$ test for categorical variables and an unpaired t test for continuous variables, and used uni- and multivariable logistic regression models to determine the association of baseline characteristics with 30-day mortality. The propensity scores of SAVR patients were estimated using a probit model with all baseline characteristics as described above as independent variables. The propensity score is the probability that a patient would have been treated with SAVR given that patient's observed baseline characteristics. Patients with the same propensity score must have the same distribution of baseline characteristics. To determine whether this assumption of balanced baseline characteristics was satisfied, we used standard algorithms implemented in the statistical package. Then, we calculated the cstatistic (the area under the receiver operating characteristics curve for the ability of propensity scores to predict actual treatment) as an estimate of the adequacy of the model.

To ensure the quality of the matching using propensity scores, we applied the common support assumption. The common support assumption indicates that patients with the same propensity score have a non-zero probability of receiving both, TAVI or SAVR ${ }^{18}$. If probability densities are too low in one of the groups, there is insufficient overlap of propensity scores and the assumption of common support is unlikely to be satisfied. To address this, we estimated the probability densities of propensity scores of patients in 
the TAVI and SAVR group using Epanechnikov kernel probability density estimates based on propensity score increments of $0.025^{19}$. We pre-specified a probability density of $>0.5$ to ensure sufficient overlap of propensity scores ${ }^{20}$. Below this pre-specified probability density (established at a propensity score $<0.675$ ), patients who had undergone TAVI were considered unlikely to be comparable with patients of the same propensity score who had undergone SAVR We used logistic regression models to compare 30-day mortality between groups. We pre-specified the following seven approaches for analysis: (1) crude univariable analysis; (2) multivariable analysis adjusted for all baseline characteristics described above; (3) bivariable analysis adjusted for the propensity score as a linear term ${ }^{21}$; (4) multivariable analysis adjusted for the propensity score and for all baseline characteristics; (5) univariable analysis after caliper matching on the propensity score in a range of $\pm 0.05^{22}$; (6) weighted univariable analysis using the inverse probability of treatment (IPT) as weights ${ }^{23,24}$; (7) IPT weighted multivariable analysis adjusted for all baseline characteristics. The IPT weighted analyses used the inverse of the propensity score as weights in SAVR patients and the inverse of 1 minus the propensity score in TAVI patients. All analyses were based on logistic regression models and were performed in the overall dataset and stratified according to presence or absence of sufficient overlap of propensity scores (propensity score $<0.675$ versus $\geq 0.675$ ). To determine whether there was an interaction between estimated odds ratios of death and overlap of propensity scores, we performed a formal interaction test based on z-scores. Then, we

Table 1. Baseline characteristics.

\begin{tabular}{|c|c|c|c|c|}
\hline & $\begin{array}{l}\text { Transcatheter aortic } \\
\text { valve implantation } \\
(n=114)\end{array}$ & $\begin{array}{c}\text { Surgical aortic } \\
\text { valve replacement } \\
(n=1008)\end{array}$ & Difference $(95 \% \mathrm{CI})$ * & $\mathbf{P}$ \\
\hline Age, y (SD) & $82.8(5.5)$ & $69.9(11.4)$ & $12.9(10.8$ to 15.1$)$ & $<0.001$ \\
\hline Female, n (\%) & $64(56.1 \%)$ & $408(41.5 \%)$ & $15.7 \%$ ( 6.1 to $25.3 \%)$ & 0.001 \\
\hline Logistic EuroSCORE, \% (SD) & $20.1(13.4)$ & $9.1(10.2)$ & $11.0(9.0$ to 13.1$)$ & $<0.001$ \\
\hline $\begin{array}{l}\text { NYHA class, n (\%) } \\
\text { I } \\
\text { II } \\
\text { III } \\
\text { IV }\end{array}$ & $\begin{array}{c}1(0.9 \%) \\
14(12.3 \%) \\
78(68.4 \%) \\
21(18.4 \%)\end{array}$ & $\begin{array}{l}147(14.6 \%) \\
403(40.0 \%) \\
356(35.3 \%) \\
102(10.1 \%)\end{array}$ & & $<0.001^{* *}$ \\
\hline Diabetes mellitus, n (\%) & $26(22.8 \%)$ & $243(24.1 \%)$ & $-1.3 \%(-9.4$ to $6.8 \%)$ & 0.76 \\
\hline Hypertension, n (\%) & $72(63.1 \%)$ & $631(62.6 \%)$ & $0.6 \%(-8.8$ to $9.9 \%)$ & 0.91 \\
\hline Coronary artery disease, $\mathrm{n}(\%)$ & $64(56.1 \%)$ & $512(50.8 \%)$ & $5.3 \%(-4.3$ to $15.0 \%)$ & 0.28 \\
\hline Previous coronary bypass surgery, $\mathrm{n}(\%)$ & $28(24.6 \%)$ & $42(4.2 \%)$ & $20.4 \%$ (12.4 to $28.4 \%)$ & $<0.001$ \\
\hline $\begin{array}{l}\text { Left ventricular ejection fraction, } \mathrm{n}(\%) \\
\begin{array}{l}>50 \% \\
30-50 \% \\
<30 \%\end{array}\end{array}$ & $\begin{array}{c}67(58.8 \%) \\
40(35.1 \%) \\
7(6.1 \%)\end{array}$ & $\begin{array}{c}834(82.7 \%) \\
135(13.4 \%) \\
39(3.9 \%)\end{array}$ & & $<0.001^{* *}$ \\
\hline Atrial fibrillation, n (\%) & $22(19.3 \%)$ & $90(8.9 \%)$ & $10.4 \%$ (2.9 to $17.8 \%)$ & $<0.001$ \\
\hline Cereberovascular disease, $\mathrm{n}(\%)$ & $20(17.5 \%)$ & $50(5.0)$ & $12.6 \%(5.5$ to $19.7 \%)$ & $<0.001$ \\
\hline Peripheral vascular disease, $\mathrm{n}(\%)$ & $21(18.4 \%)$ & $47(4.7 \%)$ & $13.8 \%$ ( 6.5 to $21.0 \%)$ & $<0.001$ \\
\hline COPD, n (\%) & $24(21.1 \%)$ & $134(13.3 \%)$ & $7.8 \%(0.0$ to $15.5 \%)$ & 0.024 \\
\hline Pulmonary hypertension, $\mathrm{n}(\%)$ & $34(29.8 \%)$ & $86(8.5 \%)$ & $21.3 \%$ (12.7 to $29.9 \%)$ & $<0.001$ \\
\hline Creatinine, umol/L (SD) & $114(92.9)$ & $98.6(61.5)$ & 15.7 (3.0 to 28.3 ) & 0.016 \\
\hline Creatinine above $200 \mathrm{umol} / \mathrm{L}, \mathrm{n}(\%)$ & $7(6.1 \%)$ & $31(3.1 \%)$ & $3.1 \%(-1.5$ to $7.6 \%)$ & 0.086 \\
\hline MI within 90 days of procedure, $\mathrm{n}(\%)$ & $4(3.5 \%)$ & $34(3.4 \%)$ & $0.1 \%(-3.4$ to $3.7 \%)$ & 0.94 \\
\hline
\end{tabular}

COPD: chronic obstructive pulmonary disease; MI: myocardial infarction; NYHA: New York Heart Association; *Differences relate to percentages for dichotmous

variables and means for continuous variables; ${ }^{* *}$ Test for trend performed a sensitivity analysis (not pre-specified), additionally adjusting IPT weighted analyses restricted to patients with propensity scores $\geq 0.675$ for the procedural characteristics described above. Finally, we considered patients undergoing TAVI with propensity scores $\geq 0.675$ to be potentially eligible for a randomised comparison of TAVI and SAVR and compared pre-treatment characteristics of these patients with characteristics of patients undergoing TAVI with propensity scores $<0.675$ who were deemed ineligible for a randomised comparison with SAVR. All p-values are two-sided. Statistical analyses were performed using Stata Version 10 (Stata Corporation, College Station, TX, USA).

\section{Results}

Between January 2006 and December 2008, 1,633 consecutive patients underwent invasive treatment for aortic stenosis using TAVI or SAVR. After exclusion of 508 patients because of a primary diagnosis of aortic regurgitation, multiple valve surgery, or concomitant aortic root surgery, 1,122 patients (1,122 procedures) were included in the study: 114 undergoing TAVI (52 Bern and 62 Rotterdam) and 1,008 patients undergoing SAVR ( 645 Bern and 363 Rotterdam). No patient was lost to follow-up at 30 days after the index procedure.

\section{Baseline characteristics of patients}

Baseline characteristics of the TAVI and SAVR patients are summarised in Table 1. Compared to patients undergoing SAVR, patients with TAVI were clearly older, more often female, more likely 
to be in NYHA class III and IV, had a considerably higher logistic EuroSCORE and more comorbid conditions, including previous coronary artery bypass surgery, left ventricular dysfunction, atrial fibrillation, cerebral and peripheral vascular disease, chronic obstructive pulmonary disease, and pulmonary hypertension.

\section{Procedural characteristics}

The procedure was performed as an emergency measure in two TAVI patients (1.8\%) and 43 SAVR patients (4.3\%) (difference $-2.4 \%, 95 \%$ confidence interval $[\mathrm{Cl}]-5.1$ to $0.3 \%$ ). Concomitant revascularisation was performed in $10 \mathrm{TAVI}$ patients (8.8\%) and 436 SAVR patients (43.5\%) (difference $-34.7 \%, 95 \% \mathrm{Cl}-40.7$ to $-28.7 \%$ ). An additional $10 \mathrm{TAVI}$ patients (8.8\%) had coronary revascularisation within four weeks prior to valve implantation as a staged procedure.

\section{Association of baseline characteristics with 30-day mortality}

Table 2 presents the crude and adjusted odds ratios for 30-day mortality. Univariable analysis revealed that age, logistic EuroSCORE, previous coronary artery bypass, atrial fibrillation, renal failure (creatinine $>200 \mu \mathrm{mol} / \mathrm{L}$ ) and myocardial infarction within 90 days of the procedure were associated with 30-day mortality at $p<0.05$; a trend was noted for diabetes mellitus $(p=0.051)$. In multivariable analysis, only logistic EuroSCORE and atrial fibrillation were associated with mortality at $p<0.05$, and a trend remained for diabetes mellitus $(p=0.089)$.

\section{Propensity scores}

The model used to estimate propensity scores yielded a c-statistic of 0.93 . Figure 1 shows the distribution of propensity scores. The mean propensity score to receive SAVR was $0.53 \pm 0.28$ for patients undergoing TAVI compared with $0.94 \pm 0.12$ for patients actually undergoing SAVR. The distribution was symmetrical around 0.5 for the TAVI group, but clearly shifted towards 1 for the SAVR group. Based on the common support assumption, the area of sufficient overlap of propensity scores was small (Figure 1 , white area to the right): in patients undergoing SAVR, the probability density fell definitely below the pre-specified value of 0.5 at a propensity score of 0.675 . In patients undergoing TAVI, 39 patients (34.2\%) were above and 75 (65.8\%) were below the cut-off of 0.675. In patients undergoing SAVR, 957 patients (94.9\%) were above and 51 (5.1\%) were below the cut-off. Using simply the propensity scores with a calliper matching range of 0.05, 81 patients undergoing TAVI (71.1\%) could each be matched to a patient in the SAVR group. Of these 81 pairs of patients, 39 were above and 42 pairs were below the cut-off of 0.675 .

\section{Impact of different approaches used for control of confounding on mortality estimates in overall dataset}

Figure 2 presents the results of the stepwise procedure to control for confounding in the analysis of the overall dataset. Within 30 days of the index procedure, 11 patients $(9.6 \%)$ who had undergone

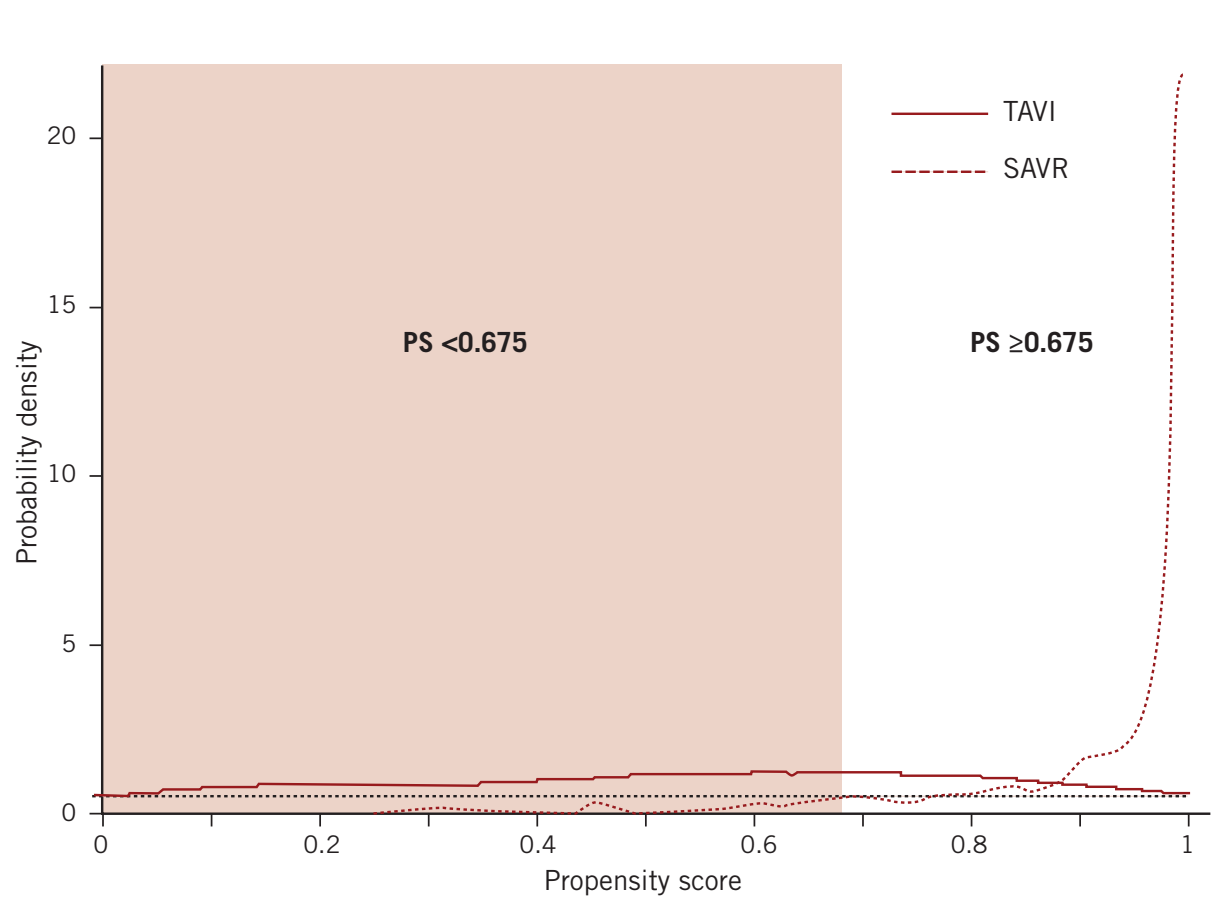

Figure 1. Probability density function of the propensity score for 114 patients undergoing TAVI (red solid line) and 1,008 patients undergoing SAVR (red dotted line). The black dotted line represents the pre-specified probability density of $>0.5$; propensity score matching above this probability density ensures sufficient overlap of propensity scores. The white area indicates the range of propensity scores with sufficient overlap (propensity score $\geq 0.675$ ) and identifies patients potentially eligible for a randomised comparison of TAVI and SAVR. The coloured area indicates the range of propensity scores with insufficient overlap and identifies patients likely to be ineligible for a randomised comparison. 
Table 2. Crude and adjusted odds ratios (OR) for 30-day mortality.

\begin{tabular}{|c|c|c|c|c|}
\hline & Crude OR $(95 \% \mathrm{CI})$ & $\mathbf{P}$ & Adjusted OR (95\% CI) & $\mathbf{P}$ \\
\hline Age (per 10 years) & $1.46(1.01$ to 2.11$)$ & 0.043 & $1.06(0.71$ to 1.59$)$ & 0.78 \\
\hline Female & $1.39(0.70$ to 2.75$)$ & 0.34 & 1.28 (0.59 to 2.75$)$ & 0.53 \\
\hline Logistic EuroSCORE (per 10\%) & $1.61(1.35$ to 1.91$)$ & $<0.001$ & 1.65 (1.20 to 2.25$)$ & 0.002 \\
\hline $\begin{array}{l}\text { NYHA class } \\
\text { I } \\
\text { II } \\
\text { III } \\
\text { IV }\end{array}$ & $\begin{array}{l}\text { Reference category } \\
1.25(0.26 \text { to } 6.07) \\
3.16(0.72 \text { to } 13.78) \\
4.41(0.90 \text { to } 21.61)\end{array}$ & 0.005 & $\begin{array}{l}\text { Reference category } \\
1.11(0.22 \text { to } 5.55) \\
1.64(0.35 \text { to } 7.67) \\
1.74(0.32 \text { to } 9.58)\end{array}$ & 0.32 \\
\hline Diabetes Mellitus & 2.01 (0.99 to 4.07$)$ & 0.052 & $1.97(0.90$ to 4.30$)$ & 0.089 \\
\hline Hypertension & $1.25(0.61$ to 2.60$)$ & 0.54 & 0.95 (0.43 to 2.12$)$ & 0.91 \\
\hline Coronary artery disease & 1.37 (0.68 to 2.73$)$ & 0.38 & $0.82(0.36$ to 1.88$)$ & 0.65 \\
\hline Previous CABG & $1.35(0.39$ to 4.64$)$ & 0.64 & 1.35 (0.39 to 4.64$)$ & 0.64 \\
\hline $\begin{array}{l}\text { Left ventricular ejection fraction } \\
\qquad \begin{array}{l}>50 \% \\
30-50 \% \\
<30 \%\end{array}\end{array}$ & $\begin{array}{l}\text { Reference category } \\
1.03(0.39 \text { to } 2.73) \\
3.34(1.11 \text { to } 10.02)\end{array}$ & 0.10 & $\begin{array}{l}\text { Reference category } \\
0.41(0.14 \text { to } 1.23) \\
1.04(0.23 \text { to } 4.72)\end{array}$ & 0.44 \\
\hline Atrial fibrillation & 4.03 (1.87 to 8.66$)$ & $<0.001$ & 4.75 (2.10 to 11.26$)$ & $<0.001$ \\
\hline Cereberovascular disease & $0.94(0.22$ to 3.99$)$ & 0.93 & $0.43(0.09$ to 2.15$)$ & 0.30 \\
\hline Peripheral vascular disease & 1.94 (0.41 to 5.42$)$ & 0.55 & 1.49 (0.41 to 5.42$)$ & 0.55 \\
\hline COPD & $1.61(0.69$ to 3.76$)$ & 0.27 & $1.22(0.49$ to 3.07$)$ & 0.67 \\
\hline Pulmonary hypertension & 1.83 (0.74 to 4.52$)$ & 0.19 & $0.64(0.22$ to 1.84$)$ & 0.40 \\
\hline Creatinine above 200 umol/L & $4.13(1.38$ to 12.39$)$ & 0.011 & $1.87(0.49$ to 7.10$)$ & 0.36 \\
\hline MI within 90 days of procedure & $4.13(1.38$ to 12.39$)$ & 0.011 & $2.10(0.54$ to 8.16$)$ & 0.29 \\
\hline
\end{tabular}

COPD: chronic obstructive pulmonary disease; MI: myocardial infarction; NYHA: New York Heart Association

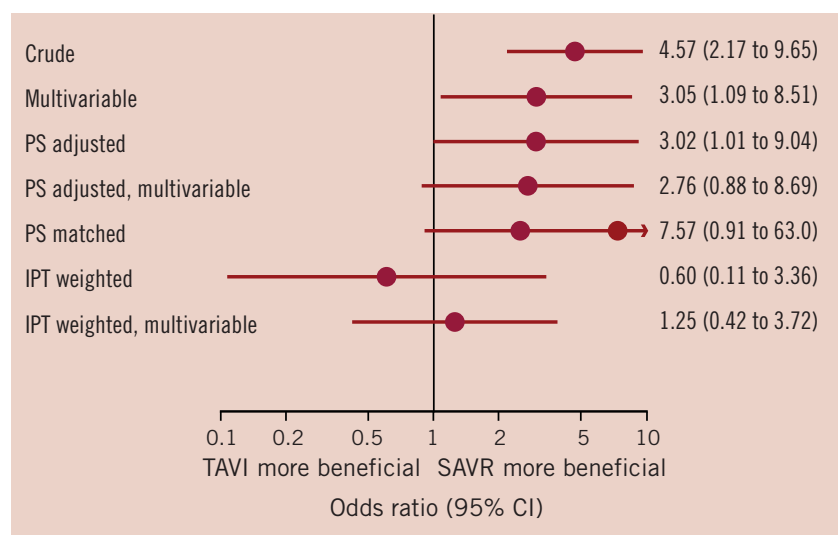

Figure 2. Impact of different approaches used to control for confounding on mortality estimates. The propensity score matched analysis was based on 162 patients (81 pairs), all other analyses were based on 1,122 patients. PS: propensity score; IPT: inverse probability of treatment.

TAVI and 23 patients (2.3\%) who had undergone SAVR died (crude odds ratio [OR] 4.57, $95 \% \mathrm{Cl}, 2.17$ to 9.65 , Figure 2). The estimated odds ratios decreased only slightly after multivariable adjustment and propensity score adjustment. This suggested an approximately threefold increase in the odds of dying with TAVI as compared with SAVR. The estimated odds ratio increased in the analysis of propensity score matched patients to 7.57 (95\% Cl 0.91 to 63.0). Conversely, when the IPT weights were used, we found the estimated odds ratios decreased to 0.60 in the univariable analysis (95\% $\mathrm{Cl} 0.11$ to 3.36 ) and to 1.25 in the multivariable analysis (95\% Cl 0.42 to 3.72 ).

\section{Analyses stratified according to overlap of propensity scores}

Figure 3 shows the results of the analyses stratified according to overlap of propensity scores. Among patients with propensity scores $\geq 0.675$ and hence sufficient overlap of propensity scores, three out of 39 patients (8.0\%) who had undergone TAVI and 22 out of 957 patients (2.8\%) who had undergone SAVR died (crude OR 3.54, 95\% Cl 1.01 to 12.3, Figure 2, top left). The estimated odds ratios decreased after multivariable adjustment (OR 2.72), propensity score adjustment (1.87), but not after propensity score matching (3.17). The 95\% Cls, however, largely overlapped the line of null effect at 1 . When using the IPT weights, we found the estimated odds ratios to decrease below 1 in both the univariable (OR $0.35,95 \% \mathrm{Cl} 0.04$ to 2.72$)$ and multivariable analyses (OR 0.87, 95\% $\mathrm{Cl} 0.19$ to 4.04). We found similar results after adjusting the IPT weighted analyses for procedural characteristics (emergency measure and concomitant revascularisation); the estimated odds ratios in patients with propensity scores $\geq 0.675$ was 0.73 (95\% Cl 0.07 to 7.70 ) after the weighted univariable analysis and $1.63(95 \% \mathrm{Cl} 0.22$ to 12.1$)$ after the weighted multivariable analysis. Among patients with insufficient overlap of propensity scores (propensity scores $<0.675)$, eight out of 75 patients $(10.7 \%$ ) who had undergone TAVI and one out of 51 patients (2.0\%) who had undergone SAVR died (crude OR 5.97, 95\% Cl 0.72 to 49.2, Figure 2, top right). The estimated odds ratios were between 5.88 and 25.7 depending on the approach used to control for confounding. Tests of interaction between estimated odds ratios and overlap were positive at the conventional significance level for univariable IPT weighted analyses ( $p=0.037$ ) and of borderline significance for multivariable IPT weighted analyses ( $p=0.051$, Figure 3 ). 


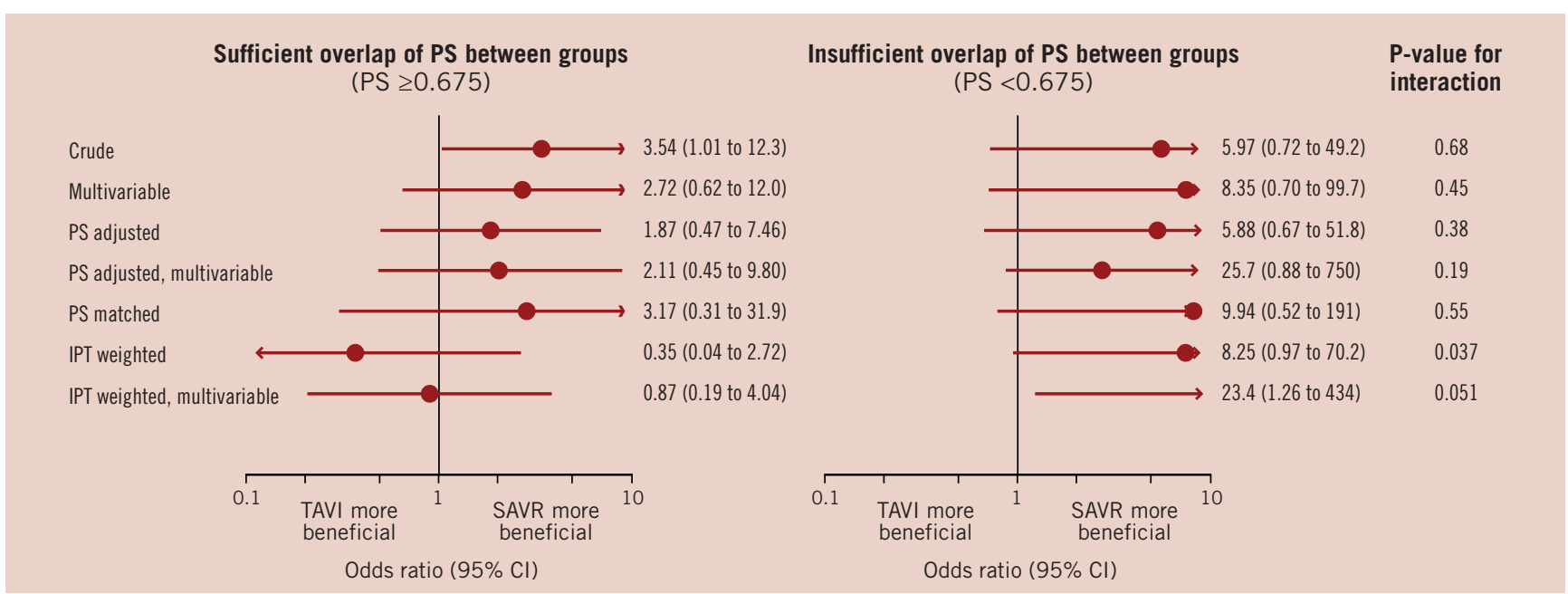

Figure 3. Analyses stratified according to overlap of propensity scores (propensity scores $\geq 0.675$ versus $<0.675$ ). Among patients with sufficient overlap (left), the propensity score matched analysis was based on 78 patients (39 pairs), all other analyses were based on 996 patients. Among patients with insufficient overlap (right), the propensity score matched analysis was based on 84 patients (42 pairs), all other analyses were based on 126 patients

\section{Patients potentially eligible for a randomised trial} Table 3 presents the baseline characteristics of TAVI patients who had propensity scores $\geq 0.675$ and were considered to be potentially eligible for a randomised comparison of TAVI and SAVR compared with the characteristics of TAVI patients with propensity scores $<0.675$ deemed to be ineligible. Patients eligible for a randomised trial were younger, had less severe symptoms as measured by the NYHA class, had lower logistic EuroSCORES, and were less likely to report a history of previous coronary artery bypass, atrial fibrillation, stroke, peripheral vascular disease, or pulmonary hypertension.

\section{Discussion}

In this prospective cohort study we found that both measured and unmeasured confounding complicated the observational comparison of 30-day mortality of TAVI versus SAVR. Compared to SAVR patients, TAVI patients were clearly older, more often female, more likely to be in NYHA class III and IV, had a considerably higher logistic EuroSCORE and had more comorbid conditions, including previous coronary artery bypass surgery, left ventricular dysfunction, atrial fibrillation, cerebral and peripheral vascular disease, chronic obstructive pulmonary disease, and pulmonary hypertension. When naively analysing the overall dataset of 1,122 consecutive patients included in our study, we found a 4.5-fold increase in the odds of death associated with TAVI as compared with SAVR. The odds ratio, however, ranged from 0.6 to 7.57 depending on the method used to control for confounding. These results indicate that TAVI may be associated with potential benefits or harm. Given the fact that TAVI was performed in either high risk or inoperable patients, analysis of the overall dataset may suffer from confounding by indication. For the inoperable patients, the relevant comparison would have been medically managed patients. In order to minimise confounding by indication, we identified patients from the TAVI and SAVR group who, in addition to having similar propensity scores, would also be appropriate for either type of treatment.
Below a propensity score cut-off of 0.675 , it was deemed unlikely that two patients with the same propensity score, one who actually received TAVI, the other SAVR, had indeed identical probabilities to undergo SAVR. Two-thirds of patients undergoing TAVI, but only $5 \%$ of those undergoing SAVR had scores below this cut-off. Restricting the analysis to patients with sufficient overlap of propensity scores $\geq$ 0.675, we found little evidence for an excess mortality in TAVI patients. On the other hand, the estimated odds ratios greatly increased between 5.9 and 25.7 in those patients with insufficient overlap of propensity scores. These results suggest that unmeasured confounding factors complicated the observational comparisons of TAVI versus SAVR, albeit more in patients with insufficient than sufficient overlap of propensity scores. Examples of unmeasured confounding variables that could be associated with both the selection of treatment and prognosis include porcelain aorta, history of mediastinal radiation, or frailty. In addition, we were unable to record the clinical judgment of the treating physicians, which may be a relevant proxy for prognosis. In light of the high probability of residual confounding complicating any observational study in this field, randomised controlled trials comparing TAVI and SAVR are clearly warranted.

Through our examination of propensity score distributions, we characterised a subgroup of TAVI patients likely to be eligible for a randomised trial (Table 3). In our institutions, the following criteria are used to guide the selection of patients for TAVI: age $\geq 75$ years, a logistic EuroSCORE $\geq 15 \%$, and/or age $\geq 65$ years associated with severe limiting comorbid conditions. Our study indicates that approximately one-third of patients selected for TAVI (based on these criteria) would be eligible for a randomised comparison of TAVI and SAVR. These patients were younger, had lower logistic EuroScores, and were less likely to report a history of previous coronary artery bypass, atrial fibrillation, stroke, peripheral vascular disease, or pulmonary hypertension than potentially ineligible TAVI patients. Based on the exploratory nature of our study, we cannot provide 
Table 3. Comparison of patients with transcatheter aortic valve implantation potentially eligible for a randomised trial (propensiity score $\geq 0.675$ ) with those likely to be ineligible (propensity score $<0.675$ )

\begin{tabular}{|c|c|c|c|c|}
\hline & $\begin{array}{c}\text { Eligible } \\
(n=39)\end{array}$ & $\begin{array}{c}\text { Ineligible } \\
(n=75)\end{array}$ & Difference $(95 \% \mathrm{CI}) *$ & $\mathbf{P}$ \\
\hline Age, y (SD) & $79.3(5.8)$ & $84.7(4.4)$ & $-5.3(-7.3$ to -3.43$)$ & $<0.001$ \\
\hline Female, n (\%) & $23(60.0 \%)$ & $41(54.7 \%)$ & $4.3 \%(-14.8$ to $23.4 \%)$ & 0.66 \\
\hline Logistic EuroSCORE, \% (SD) & $15.7(10.4)$ & $22.4(14.25)$ & $-6.7(-11.9$ to -1.6$)$ & 0.010 \\
\hline $\begin{array}{l}\text { NYHA class, n (\%) } \\
\text { I } \\
\text { II } \\
\text { III } \\
\text { IV }\end{array}$ & $\begin{aligned} 0 & (0 \%) \\
11 & (28.2 \%) \\
22 & (56.4 \%) \\
6 & (15.4 \%)\end{aligned}$ & $\begin{array}{c}1(1.3 \%) \\
3(4.0 \%) \\
56(74.7 \%) \\
15(20.0 \%)\end{array}$ & & 0.002 \\
\hline Diabetes Mellitus, n (\%) & $7(17.9 \%)$ & $19(25.3 \%)$ & $-7.4 \%(-22.9$ to $8.2 \%)$ & 0.37 \\
\hline Hypertension, n (\%) & $25(64.1 \%)$ & $47(62.7 \%)$ & $1.4 \%(-17.2$ to $20.1 \%)$ & 0.88 \\
\hline Coronary artery disease, $\mathrm{n}(\%)$ & $19(48.7 \%)$ & $45(60.0 \%)$ & $-11.3 \%(-30.5$ to $7.9 \%)$ & 0.25 \\
\hline Previous CABG, $\mathrm{n}(\%)$ & $2(5.1 \%)$ & $26(34.7 \%)$ & $-29.5 \%(-42.3$ to $-16.7 \%)$ & $<0.001$ \\
\hline $\begin{array}{l}\text { Left ventricular ejection fraction, } \mathrm{n}(\%) \\
\quad>50 \% \\
\quad 30-50 \% \\
<30 \%\end{array}$ & $\begin{aligned} 29 & (74.4 \%) \\
8 & (20.5 \%) \\
2 & (5.1 \%)\end{aligned}$ & $\begin{array}{c}38(50.7 \%) \\
32(42.7 \%) \\
5(6.7 \%)\end{array}$ & & 0.037 \\
\hline Atrial fibrillation, n (\%) & $3(7.7 \%)$ & $19(25.3 \%)$ & $-17.6 \%(-30.6$ to $-4.7 \%)$ & 0.024 \\
\hline Cereberovascular disease, n (\%) & $3(7.7 \%)$ & $17(22.7 \%)$ & $-15.0 \%(-27.6$ to $-2.3 \%)$ & 0.046 \\
\hline Peripheral vascular disease, $\mathrm{n}(\%)$ & $3(7.7 \%)$ & $18(24.0 \%)$ & $-16.3 \%(-29.1$ to $-3.5 \%)$ & 0.033 \\
\hline COPD, n (\%) & $6(15.4 \%)$ & $18(24.0 \%)$ & $-8.6 \%(-23.5$ to $6.3 \%)$ & 0.28 \\
\hline Pulmonary hypertension, $\mathrm{n}(\%)$ & $6(15.4 \%)$ & $28(37.3 \%)$ & $-21.9 \%(-37.7$ to $-6.2 \%)$ & 0.015 \\
\hline Creatinine, umol/L (SD) & $97(42)$ & $123(110)$ & $-27.0(-63.1$ to -9.2$)$ & 0.14 \\
\hline Creatinine above 200 umol/L, n (\%) & $1(2.6 \%)$ & $6(8.0 \%)$ & $-5.4 \%(-13.3$ to $2.5 \%)$ & 0.25 \\
\hline MI within 90 days of procedure, $n(\%)$ & $0(0 \%)$ & $4(5.3 \%)$ & $-5.3 \%(-10.4$ to $-0.2 \%)$ & 0.14 \\
\hline
\end{tabular}

COPD: chronic obstructive pulmonary disease; MI: myocardial infarction; NYHA: New York Heart Association

a firm basis for the identification of patients eligible for such a trial. The small number of patients undergoing TAVI and the small number of accumulated deaths was a limitation of this study. The multivariable analyses was difficult particularly when numbers were cut down through stratification of analyses according to overlap of propensity scores. The stratified multivariable analyses should therefore be interpreted with discretion. The small number of patients and events also meant that the most reliable analyses, which were restricted to patients with sufficient overlap of propensity scores, were imprecise. Whereas we have little evidence to suggest that TAVI is associated with increased mortality as compared with SAVR, the 95\% Cls from these analyses are wide and compatible with either substantial benefits or harms of this new intervention. The strengths of this study include the following: To our knowledge, this is a unique endeavour to compare the characteristics and outcomes of patients with aortic stenosis undergoing TAVI and SAVR. Secondly, an interdisciplinary team of cardiologists, cardiac surgeons, statisticians and clinical epidemiologists performed a thorough examination of the potential for measured and unmeasured confounding. Thirdly, we had complete follow-up within the first 30 days of the index procedure.

The unadjusted 30-day mortality rates were $9.6 \%$ and $2.3 \%$, for TAVI and SAVR groups, respectively. The results for the TAVI group compare favourably with contemporary outcome reports for the CoreValve ReValving System ${ }^{1-3}$. The 30-day mortality rate for the SAVR group was more than two times lower than the unadjusted mortality rate of 5.7\% reported by Rankin et al for 216,245 patients undergoing single aortic valve replacement ${ }^{25}$. The TAVI group was mainly comprised of octogenarians and approximately $40 \%$ of patients had left ventricular dysfunction (EF <50\%). Table 4 presents the in-hospital mortality rates of high-risk patients undergoing SAVR. The 30-day mortality rate of $9.6 \%$ observed in TAVI patients in our study is encouraging in light of the reported inhospital mortality rates of selected octogenarians (4.6\% to $13.5 \%)^{4-11}$ patients with left ventricular dysfunction (6\% to $33 \%)^{12,13,26-31}$ and patients with high logistic EuroSCORES (7.8\%) undergoing surgical aortic valve replacement ${ }^{32}$.

While surgical heart valve replacement remains the standard of care, several studies have demonstrated that $30 \%$ to $60 \%$ of patients with symptomatic severe aortic valve stenosis are denied or not referred for surgery ${ }^{33-36}$. Patients who are denied or not referred for surgical aortic valve replacement are typically older, have moderate impairment of ejection fraction and more non-cardiac co-morbidities than patients undergoing valve surgery ${ }^{33-36}$. TAVI meets an unmet clinical need in these patients and may therefore be considered a breakthrough technology ${ }^{37}$.

\section{Conclusions}

Both measured and unmeasured confounding limits the conclusions that can be drawn from observational comparisons of TAVI versus SAVR. Our study indicates that TAVI could be associated with either substantial benefits or harms. Randomised 
Table 4. In-hospital mortality in high-risk patient subsets undergoing surgical aortic valve replacement.

\begin{tabular}{|c|c|c|c|}
\hline Reference & Number of patients & Patient characteristics & In-hospital mortality \\
\hline \multicolumn{4}{|c|}{ Octogenarians } \\
\hline de Vincentis $(2008)^{4}$ & 345 & $>80$ years $(70 \% \mathrm{CABG})$ & $7.5 \%$ \\
\hline Gulbins $(2008)^{5}$ & 236 & $>80$ years $(91 \%$ CABG $)$ & $9.3 \%$ \\
\hline Filsoufi $(2008)^{11}$ & 231 & $\geq 80$ years $(48 \%$ CABG $)$ & $5.2 \%$ \\
\hline Melby $(2007)^{6}$ & 245 & $\geq 80$ years $(57 \%$ CABG $)$ & $9.0 \%$ \\
\hline Kolh $(2007)^{7}$ & 220 & $\geq 80$ years $(26 \%$ CABG $)$ & $9.0 \%$ \\
\hline Bose $(2007)^{10}$ & 68 & $\geq 80$ years $(46 \%$ CABG $)$ & $13.0 \%$ \\
\hline Langanay $(2006)^{8}$ & 442 & $\geq 80$ years $(19 \%$ CABG $)$ & $7.5 \%$ \\
\hline Asimakopoulos $(1997)^{9}$ & 1100 & $\geq 80$ years & $6.6 \%$ \\
\hline \multicolumn{4}{|c|}{ Left ventricular dysfunction } \\
\hline Clavel $(2008)^{26}$ & 44 & $\mathrm{EF} \leq 40 \%, \mathrm{MG} \leq 40 \mathrm{mmHg}$ & $18.0 \%$ \\
\hline Levy $(2008)^{27}$ & 217 & $\mathrm{EF} \leq 35 \%, \mathrm{MG} \leq 30 \mathrm{mmHg}$ & $16.0 \%$ \\
\hline Quere $(2006)^{12}$ & $66^{*}$ & $\mathrm{EF} \leq 40 \%, \mathrm{MG} \leq 40 \mathrm{mmHg}$ & $14.1 \% * *$ \\
\hline Tarantini $(2003)^{28}$ & 52 & $\mathrm{EF} \leq 35 \%$ & $8.0 \%$ \\
\hline Sharony $(2003)^{29}$ & 260 & $E F \leq 40 \%$ & $9.6 \%$ \\
\hline Pereira $(2002)^{30}$ & 68 & $\mathrm{EF} \leq 35 \%, \mathrm{MG} \leq 30 \mathrm{mmHg}$ & $8.0 \%$ \\
\hline Powell $(2000)^{31}$ & 55 & $E F \leq 30 \%$ & $18.0 \%$ \\
\hline \multicolumn{4}{|c|}{ High risk based on logistic EuroSCORE } \\
\hline Grossi $(2008)^{32}$ & 731 & Mean logistic EuroSCORE $17.0 \%$ & $7.8 \%$ \\
\hline
\end{tabular}

${ }^{*} 70 \%$ of patients with contractile reserve and $30 \%$ without contractile reserve; ${ }^{* *}$ Represents the weighted average of the $6.0 \%$ mortality for patients with contractile reserve and $33 \%$ mortality for patients without contractile reserve

comparisons of TAVI and SAVR are warranted to provide evidencebased medicine and legitimise the use of TAVI in the eyes of the medical community, non-invasive cardiologist, cardiac surgeon, and health authorities. In addition, these trials will play a crucial role in reimbursement policies.

\section{Acknowledgements}

We are grateful to Jonathan Sterne and Marcel Zwahlen for helpful discussions related to the analytical strategies used in this study. The analysis was funded by intramural grants provided by CTU Bern, Bern University Hospital, the Institute of Social and Preventive Medicine, University of Bern, and the Swiss National Science Foundation to Peter Jüni, a PROSPER fellow funded by the Swiss National Science Foundation. CTU Bern is supported by the Swiss National Science Foundation.

\section{References}

1. Webb JG, Pasupati S, Humphries K, Thompson C, Altwegg L, Moss R, Sinhal A, Carere RG, Munt B, Ricci D, Ye J, Cheung A, Lichtenstein SV. Percutaneous transarterial aortic valve replacement in selected high-risk patients with aortic stenosis. Circulation 2007;116:755763.

2. Piazza N, Grube E, Gerckens U, den Heijer P, Linke A, Luha O, Ramondo A, Ussia G, Wenaweser P, Windecker S, Laborde JC, de Jaegere P, Serruys PW. Procedural and 30-day outcomes following transcatheter aortic valve implantation using the third generation (18F) CoreValve ReValving System - Results from the Multicenter, Expanded Evaluation Registry 1-year following CE mark approval. Eurolntervention 2008;4:242-249.

3. Grube E, Buellesfeld L, Mueller R, Sauren B, Zickmann B, Nair D, Beucher H, Felderhoff T, Iversen S, Gerckens U. Progress and current status of percutaneous aortic valve replacement:Results of three device generations of the CoreValve ReValving System. Circ Cardiovasc Intervent 2008;1:167-175.

4. de Vincentiis C, Kunkl AB, Trimarchi S, Gagliardotto P, Frigiola A, Menicanti L, Di Donato M. Aortic valve replacement in octogenarians:is biologic valve the unique solution? Ann Thorac Surg 2008;85:1296-1301.

5. Gulbins H, Malkoc A, Ennker J. Combined cardiac surgical procedures in octogenarians:operative outcome. Clin Res Cardiol 2008;97:176-180.

6. Melby SJ, Zierer A, Kaiser SP, Guthrie TJ, Keune JD, Schuessler RB, Pasque MK, Lawton JS, Moazami N, Moon MR, Damiano RJ, Jr. Aortic valve replacement in octogenarians:risk factors for early and late mortality. Ann Thorac Surg 2007;83:1651-1656; discussion 1656-1657.

7. Kolh P, Kerzmann A, Honore C, Comte L, Limet R. Aortic valve surgery in octogenarians:predictive factors for operative and long-term results. Eur J Cardiothorac Surg 2007;31:600-606.

8. Langanay T, Verhoye JP, Ocampo G, Vola M, Tauran A, De La Tour B, Derieux $\mathrm{T}$, Ingels $\mathrm{A}$, Corbineau $\mathrm{H}$, Leguerrier A. Current hospital mortality of aortic valve replacement in octogenarians. J Heart Valve Dis 2006;15(5):630-637; discussion 637.

9. Asimakopoulos G, Edwards MB, Taylor KM. Aortic valve replacement in patients 80 years of age and older:survival and cause of death based on 1100 cases:collective results from the UK Heart Valve Registry. Circulation 1997;96:3403-3408.

10. Bose AK, Aitchison JD, Dark JH. Aortic valve replacement in octogenarians. J Cardiothorac Surg 2007;2:33.

11. Filsoufi F, Rahmanian PB, Castillo JG, Chikwe J, Silvay G, Adams DH. Excellent early and late outcomes of aortic valve replacement in people aged 80 and older. J Am Geriatr Soc 2008;56:255-261.

12. Quere JP, Monin JL, Levy F, Petit H, Baleynaud S, Chauvel C, Pop C, OhImann P, Lelguen C, Dehant P, Gueret P, Tribouilloy C. Influence of preoperative left ventricular contractile reserve on postoperative ejection fraction in low-gradient aortic stenosis. Circulation 2006;113:1738-1744. 
13. Subramanian H, Kunadian B, Dunning J. Is it ever worth contemplating an aortic valve replacement on patients with low gradient severe aortic stenosis but poor left ventricular function with no contractile reserve? Interactive cardiovascular and thoracic surgery 2008;7:301-305.

14. de Jaegere P, van Dijk L, Laborde JC, Sianos G, Ramos FJO, Lighart J, Kappetein AP, vander Ent M, Serruys PW. True percutaneous implantation of the CoreValve aortic valve prosthesis by the combined use of ultrasound guided vascular access, Prostar XL and the TandemHeart. Eurolntervention 2007;2:500-505.

15. Piazza N, Serruys PW, de Jaegere P. Feasibility of complex coronary intervention in combination with percutaneous aortic valve implantation in patients with aortic stenosis using percutaneous left ventricular assist device (TandemHeart). Catheter Cardiovasc Interv 2009;73:161-166.

16. Nashef SA, Roques F, Michel P, Gauducheau E, Lemeshow S, Salamon R. European system for cardiac operative risk evaluation (EuroSCORE). Eur J Cardiothorac Surg 1999;16:9-13.

17. Akins CW, Miller DC, Turina MI, Kouchoukos NT, Blackstone EH, Grunkemeier GL, Takkenberg JJ, David TE, Butchart EG, Adams DH, Shahian DM, Hagl S, Mayer JE, Lytle BW. Guidelines for reporting mortality and morbidity after cardiac valve interventions. J Thorac Cardiovasc Surg 2008;135:732-738.

18. Heckman J, Lalonde R, Smith J. The economics and econometrics of active labour market programs, in A. Ashenfelter and D. Card, eds., Handbook of Labour Economics, vol. 3, Amsterdam: Elsevier Science. 1999.

19. Silverman BW. Density Estimation for Statistics and Data Analysis. Chapman and Hall, London. 1986.

20. Smith J, Todd P. Does matching overcome LaLonde's critique of nonexperimental estimators? Journal of Econometrics 2005;125:305-353.

21. D'Agostino RB, Jr. Propensity score methods for bias reduction in the comparison of a treatment to a non-randomized control group. Statistics in medicine 1998;17:2265-2281.

22. Rubin DB, Thomas N. Matching using estimated propensity scores:relating theory to practice. Biometrics 1996;52:249-264.

23. Robins JM, Hernan MA, Brumback B. Marginal structural models and causal inference in epidemiology. Epidemiology (Cambridge, Mass 2000;11:550-560.

24. Kurth T, Walker AM, Glynn RJ, Chan KA, Gaziano JM, Berger K, Robins JM. Results of multivariable logistic regression, propensity matching, propensity adjustment, and propensity-based weighting under conditions of nonuniform effect. American journal of epidemiology 2006;163:262-270.

25. Rankin JS, Hammill BG, Ferguson TB, Jr., Glower DD, O'Brien SM, DeLong ER, Peterson ED, Edwards FH. Determinants of operative mortality in valvular heart surgery. J Thorac Cardiovasc Surg 2006;131:547-557.
26. Clavel MA, Fuchs C, Burwash IG, Mundigler G, Dumesnil JG, Baumgartner H, Bergler-Klein J, Beanlands RS, Mathieu P, Magne J, Pibarot P. Predictors of outcomes in low-flow, low-gradient aortic stenosis:results of the multicenter TOPAS Study. Circulation 2008;118(14 Suppl):S234-242.

27. Levy F, Laurent M, Monin JL, Maillet JM, Pasquet A, Le Tourneau T, Petit-Eisenmann H, Gori M, Jobic Y, Bauer F, Chauvel C, Leguerrier A, Tribouilloy C. Aortic valve replacement for low-flow/low-gradient aortic stenosis operative risk stratification and long-term outcome:a European multicenter study. J Am Coll Cardiol 2008;51:1466-1472.

28. Tarantini G, Buja P, Scognamiglio R, Razzolini R, Gerosa G, Isabella G, Ramondo A, lliceto S. Aortic valve replacement in severe aortic stenosis with left ventricular dysfunction:determinants of cardiac mortality and ventricular function recovery. Eur J Cardiothorac Surg 2003;24:879-885.

29. Sharony R, Grossi EA, Saunders PC, Schwartz CF, Ciuffo GB, Baumann FG, Delianides J, Applebaum RM, Ribakove GH, Culliford AT Galloway AC, Colvin SB. Aortic valve replacement in patients with impaired ventricular function. Ann Thorac Surg 2003;75:1808-1814.

30. Pereira JJ, Lauer MS, Bashir M, Afridi I, Blackstone EH, Stewart WJ, McCarthy PM, Thomas JD, Asher CR. Survival after aortic valve replacement for severe aortic stenosis with low transvalvular gradients and severe left ventricular dysfunction. J Am Coll Cardiol 2002;39:1356-1363.

31. Powell DE, Tunick PA, Rosenzweig BP, Freedberg RS, Katz ES Applebaum RM, Perez JL, Kronzon I. Aortic valve replacement in patients with aortic stenosis and severe left ventricular dysfunction. Archives of internal medicine 2000;160:1337-1341.

32. Grossi EA, Schwartz CF, Yu PJ, Jorde UP, Crooke GA, Grau JB, Ribakove GH, Baumann FG, Ursumanno P, Culliford AT, Colvin SB, Galloway AC. High-risk aortic valve replacement:are the outcomes as bad as predicted? Ann Thorac Surg 2008;85:102-106; discussion 107.

33. Bouma BJ, van Den Brink RB, van Der Meulen JH, Verheul HA, Cheriex EC, Hamer HP, Dekker E, Lie KI, Tijssen JG. To operate or not on elderly patients with aortic stenosis:the decision and its consequences. Heart (British Cardiac Society) 1999;82:143-148.

34. Charlson E, Legedza AT, Hamel MB. Decision-making and outcomes in severe symptomatic aortic stenosis. The Journal of heart valve disease 2006;15:312-321.

35. Iung B, Cachier A, Baron G, Messika-Zeitoun D, Delahaye F, Tornos P, Gohlke-Barwolf C, Boersma E, Ravaud P, Vahanian A. Decision-making in elderly patients with severe aortic stenosis:why are so many denied surgery? Eur J H 2005;26:2714-2720.

36. Pellikka PA, Sarano ME, Nishimura RA, Malouf JF, Bailey KR, Scott CG Barnes ME, Tajik AJ. Outcome of 622 adults with asymptomatic, hemodynamically significant aortic stenosis during prolonged follow-up. Circulation 2005;111:3290-3295.

37. Food and Drug Administration Website. Guidance for industry and FDA staff:Expedited review of premarket submissions for devices. 2008; http://www.fda.gov/CDRH/mdufma/guidance/108.html 